\title{
Chapter 12 \\ Contamination of Wild Animals: Effects on Wildlife in High Radioactivity Areas of the Agricultural and Forest Landscape
}

\author{
Ken Ishida
}

\begin{abstract}
This study presents new findings related to radioactivity measurements in birds and other wild animals. High levels of radioactive contamination were found in the feathers of birds after the accident and most of this radioactivity was not washed out. However, there was little contamination in the new feathers produced by the same species after approximately 1 year. We discuss the possible effects of radioactivity, particularly cascade effects among wildlife in the Satoyama ecosystem. Satoyama consists of well-managed agricultural fields, grasslands, and several types of forests at a small-scale topography level. We describe our long-term monitoring approach.
\end{abstract}

Keywords Bush warbler $\bullet$ Cascade effect $\bullet$ Long term monitoring $\bullet$ Radioactive effect $\bullet$ Wildlife

\subsection{Introduction}

The highly radioactive plume that originated from Fukushima Daiichi nuclear power reactors 1-3 in mid-March 2011 moved toward the northwest and fell with the rain, contaminating an area of the northern Abukuma highlands in Fukushima Prefecture (Fig. 12.1). The dose rates at $1 \mathrm{~cm}$ above the ground were $20 \mu \mathrm{Sv} / \mathrm{h}$, with more in some hotspots $>30 \mathrm{~km}$ from the Fukushima Daiichi nuclear power plant (F1-NPP). The season this occurred was before the shooting of plants in the spring or the breeding of most birds and animals. The areas affected contained paddy fields, farmlands, and natural and artificial forests in the highland areas, where the

K. Ishida $(\triangle)$

Graduate School of Agricultural and Life Sciences, The University of Tokyo,

1-1-1 Yayoi, Bunkyo-ku, Tokyo 113-8657, Japan

e-mail: ishiken@es.a.u-tokyo.ac.jp 

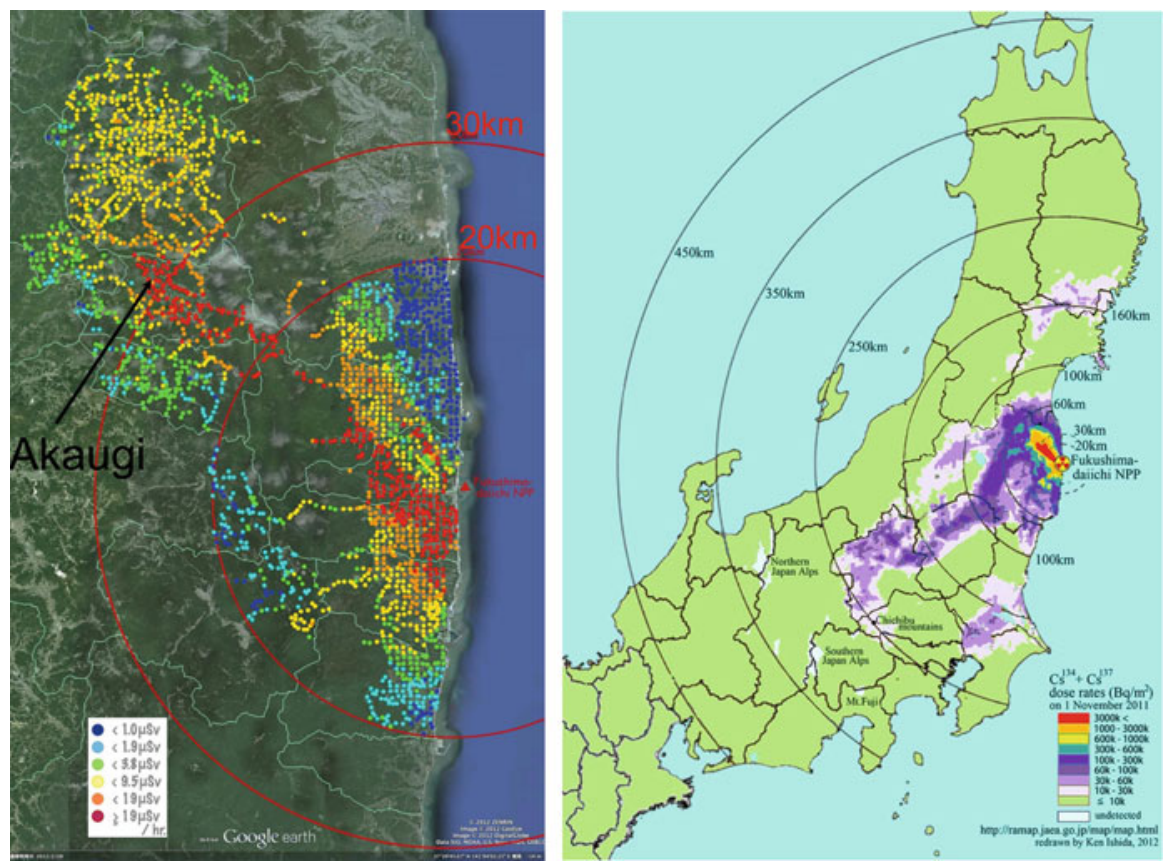

Fig. 12.1 Left, the dose rate at $1 \mathrm{~cm}$ above the ground surface in a high radioactive contamination area around and northwest of F1-NPP. The dose rates $(\mu \mathrm{Sv} / \mathrm{h})$ were measured by the survey consortium (TEPCO team) during July 4th and August 20th, 2011. Right, estimated total ${ }^{134} \mathrm{Cs}$ and ${ }^{137} \mathrm{Cs}\left(\mathrm{Bq} / \mathrm{m}^{2}\right)$ accumulation on the ground surface, based on the airborne monitoring survey conducted by MEXT from August to October 2011 (Ministry of the Education, Culture Sports, Science and Technology - Japan, November 11, 2011). All the estimated values are fitted to the assumed ones, which were at November 1st, 2011. Redrawn by the author

biodiversity is high. These areas contain more than 15 terrestrial mammals, including the macaque monkey, approximately 150 bird species, many insects, other animals, plants, and mushrooms. All residents were evacuated from this area. Thus, the wildlife was left with little or no human interferences, such as through agriculture, hunting, fishing, harvest, or automobiles.

In this study, I report the situation for birds and some mammals that inhabited the area 1.5 years after the accident. We need to understand that the condition is dynamic and the situation is changing constantly.

\subsection{Landscape of the Abukuma Highlands and Its Biodiversity}

The Abukuma Mountains cover an area of approximately $170 \mathrm{~km}$ from south to north and $40 \mathrm{~km}$ from east to west, and they are surrounded by a 10-km wide narrow plain on the Pacific coast to the east (Hamadori area), the Abukuma River plain to 


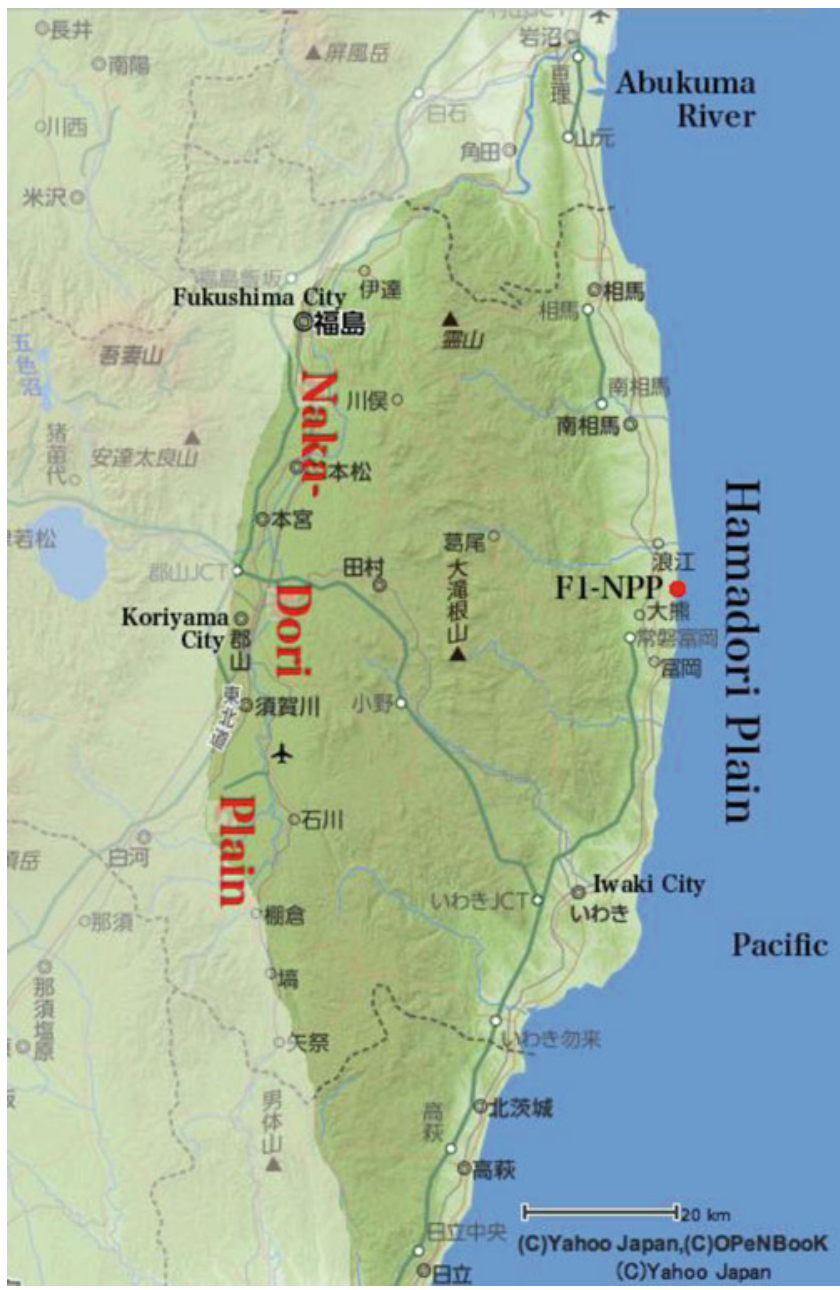

Fig. 12.2 Map of the Abukuma Mountains, the surrounding plains, and rivers. F1-NPP is located on the Pacific coast. A mountainous area covered with natural and artificial forests, paddy fields, and farmland is close to F1-NPP, which contains an abundance of wildlife

the west (Nakadori area) and the north, and the Kuji River valley to the south (Fig. 12.2). F1-NPP is located in the central east region of the Pacific coast on the Hamadori plain. Immediately behind the Hamadori plain, there are small valleys with steep streams that reach up to an altitude of approximately $400 \mathrm{~m}$. There are few houses and little human activity on these slopes. The Abukuma highlands are gentle hills at an altitude of approximately $600 \mathrm{~m}$ that reach up to $1,192 \mathrm{~m}$ and they contain a mixture of paddy fields, farmlands, secondary deciduous forest, and evergreen conifer plantations. The dominant natural tree species are Fagus japonica, Carpinus tschonoskii, Zelkova serrata, Aesculus turbinata, Pterocarya rhoifolia, Acer mono, and Abies firma. The main plantation species are Cryptomeria japonica 


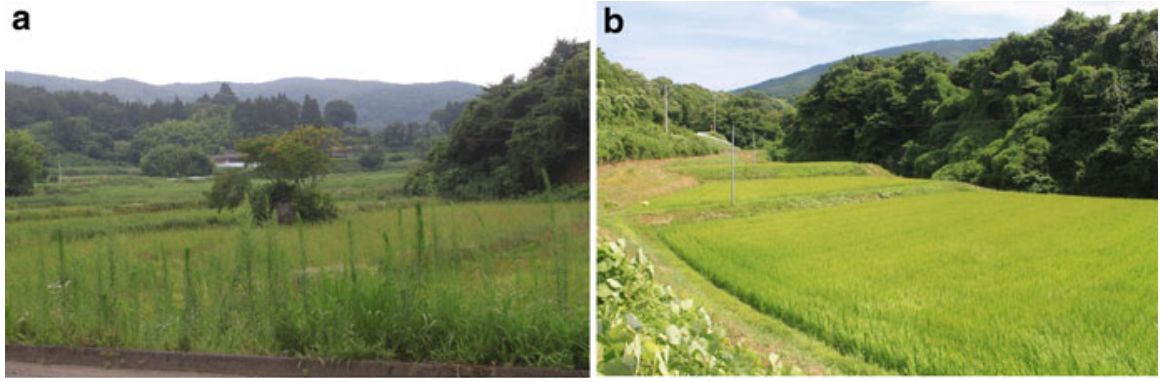

Fig. 12.3 Abandoned (left, Kawamata village) and cultivated (right, Nihonmatsu town) paddy fields in the Abukuma highlands. They were also cultivated on the slopes (right). The images were captured in August 2012. These locations were close to each other and approximately $30 \mathrm{~km}$ west of F1-NPP

and Chamaecyparis obtusa. Many small streams and ponds (Fig. 12.3, left) are scattered among the agricultural fields and forests. Thus, the ecosystem structure is heterogeneous and there are plenty of niches for wildlife. This highly humanaffected natural landscape is known as Satoyama in Japanese. ${ }^{1}$

The western Abukuma Mountains have gentle slopes and there are human residences surrounded by a Satoyama-like landscape with many small sections of paddy fields. There are streams in abundance and the small hills are covered with natural forest. Most of the western area escaped high radiation exposure; therefore, human activity has continued in this area (Fig. 12.3, right).

\subsection{The Bird Community in the Northern Abukuma Highlands}

From 1972 to 2003, Tozawa (2005) recorded 195 bird species in the northeast corner of Abukuma mountains and the connecting plain area (old Haramachi city). In a $20 \mathrm{~km}$ by $20 \mathrm{~km}$ area of the northern Abukuma highland, I recorded 52 species during 56 separate 5-min counts in May 2012 and 42 species in 38 separate 5-min counts in June 2012. The dominant species were Cettia diphone, Hypsipetes amourotis, Emberiza cioides, Cuculus policephalus, Corvus macrorhynchos, Parus major, Passer montanus, Phasianus versicolor, Streptopelia orientalis, and Carduelis sinica (Table 12.1).

The distribution of the highly dominant bush warbler ( $C$. diphone) and brown-eared bulbul (H. amourotis) was not related (negatively or positively) to the radiation levels (Fig. 12.4). Their distributions during mid-July 2011, based on 3 -min point counts in my early surveys after the accident, resembled the results obtained in 2012. When I first visited the area in 2011, the weather was not ideal for

\footnotetext{
${ }^{1}$ In Japanese, Sato means an area with human residences and activity, whereas Yama refers to hills or mountains covered with forest.
} 
Table 12.1 The ten dominant bird species and their detection rates. Birds were detected during 5 -min count surveys in an approximately $20 \mathrm{~km} \times 20 \mathrm{~km}$ area in the northern Abukuma highlands of Fukushima prefecture in May and June 2012

\begin{tabular}{lll}
\hline Species & $\begin{array}{l}\text { Rate per 56 counts from } \\
\text { April 28 to May 4 }\end{array}$ & $\begin{array}{l}\text { Rate per 38 counts from } \\
\text { June 13 to June 16 }\end{array}$ \\
\hline Cettia diphone & $46 / 56(82 \%)$ & $36 / 38(95 \%)$ \\
Hipsipetes amourotis & $37(66 \%)$ & $32(84 \%)$ \\
Emberiza cioides & $34(61 \%)$ & $24(63 \%)$ \\
Parus major & $23(41 \%)$ & $18(47 \%)$ \\
Phasianus versicolor & $20(36 \%)$ & $17(45 \%)$ \\
Corvus macrorhynchos & $13(23 \%)$ & $18(47 \%)$ \\
Passer montanus & $20(36 \%)$ & $7(18 \%)$ \\
Streptopelia orientalis & $15(27 \%)$ & $11(29 \%)$ \\
Carduelis sinica & $8(14 \%)$ & $13(34 \%)$ \\
Cuculus policephalus & 0 & $20(53 \%)$ \\
\hline
\end{tabular}

Large parts of this area were contaminated by radiation
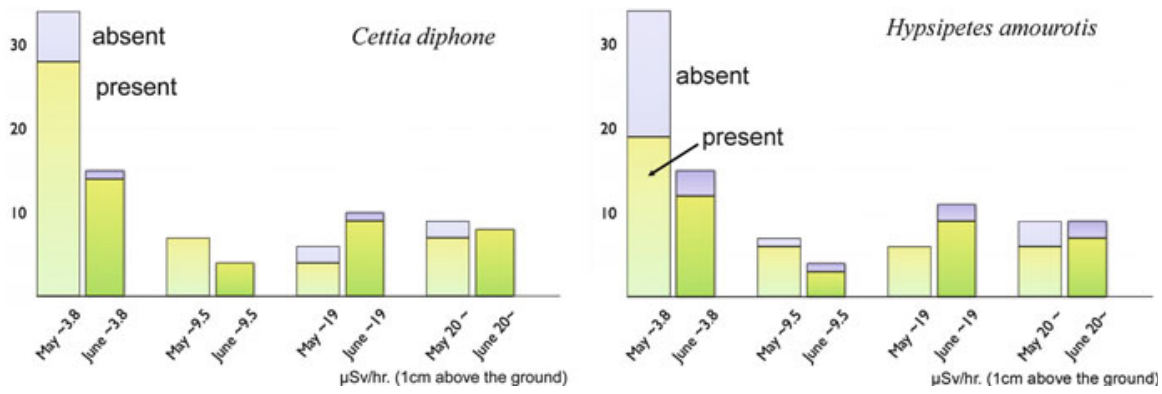

Fig. 12.4 Relationship between observation frequency and radiation levels in May and June 2012 (based on 94 separate 5-min counts), in the bush warbler (left) and the brown-eared bulbul (right)

studying the breeding bird community. The weather during summer 2011 was clearer and hotter than summer 2012 (Meteorological Agency, Japan), and I recorded only 26 bird species during 4 days. However, I recorded and caught bush warblers in the area that received the highest radiation dose, where I could enter and survey without any public permission in July and August 2011. My results are inconsistent with the conclusions published about birds in the Fukushima Daiichi area (Møller et al. 2012). It is possible that the situation was different in the two seasons of 2011 and 2012. However, the environmental cline from the center of the highlands to the west and northwest is clear; therefore, design of the bird count survey and their analyses by Møller et al. were inappropriate for discriminating the effects of radioactivity and other environmental factors. The ecosystem of the Abukuma highlands is quite complex and we need to accumulate more data to understand the wildlife activities and ecology of this area. I have been conducting automatic animal sound recording surveys since the summer of 2011. However, my analysis of the sound recordings is not yet complete. 
During early May 2012, there were no oriental cuckoos (Cululus poliocephalus), whereas they were observed 20 times in 38 count surveys (53\%) during mid-June 2012. It was not common in July or August 2012. This species is a parasite of the most dominant species, the bush warbler, and its calls are easy to detect from a distance. The presence of this parasite indicated the successful breeding of the warbler.

The top predators, the birds of prey Buteo japonicus and Strix uralensis, were common in the survey area, although their density was lower than the smaller bird species, whereas the number detected in the point count surveys during the daytime was very low. The abandoned paddy fields became dense grass bush because of the lack of agricultural management and they will soon become a secondary forest. This type of vegetation succession will not be profitable for the two main raptors, which mainly prey on small terrestrial mammals found in open grassland. This change will also possibly not be good for another raptor, Butastur indicus, which is common in the Satoyama landscape where it preys on frogs, snakes, and other animals.

The invasive alien Garrulax canorus was observed 9 times during 57 counts (21\%) in May and 10 times during 38 counts (26\%) in June. It prefers young forest and I observed it mainly around the plantation stands in the northern Abukuma highlands. The effects of this species on native species have yet to be examined.

\subsection{Bush Warbler and Its Contamination with Radioactivity}

In 2011, I captured four adult male bush warblers in mid-August using a mist net from the highly contaminated ( $>20 \mu \mathrm{Sv} / \mathrm{h}$ ) area of the Abukuma highland (Fig. 12.5). The rectrices (tail feathers) were collected and placed on imaging plates (IP) for 3 days. This yielded clear radioactive images of the feather shapes (Fig. 12.6, feather no. Dh and Di). However, the feathers collected in the Chichibu Mountains, western Saitama prefecture, approximately $250 \mathrm{~km}$ southwest of F1-NPP (Fig 12.1 right), and the feathers from a young female captured in an area with $<2 \mu \mathrm{Sv} / \mathrm{h}$ in October produced no images on the same IP (Fig. 12.6). The nuclear species and radioactivity levels of the four male feathers were measured using a germanium semiconductor detector. High doses of ${ }^{134} \mathrm{Cs}$ and ${ }^{137} \mathrm{Cs}$ were detected in all four, whereas ${ }^{110 \mathrm{~m}} \mathrm{Ag}$ was detected in eight rectrices from male $\mathrm{D}$ (Fig. 12.7, Table 12.2). One rectrix from the individual D was cleaned with Kimwipes and ethanol, followed by ultrasonic cleaning for $20 \mathrm{~min}$, but the contamination was only partially reduced (thick dots in Fig. 12.6, feather no. Di). We detected no highly contaminated points on the feathers (thick dots in Fig. 12.5, feather no. Dh and Di) during microscopic observations. Thus, very small particles with variable radioactivity levels appeared to be attached to the outside of the feather barbs and barbules. The feathers grew in 2010 during late summer, therefore, we hypothesized that this was not due to internal contamination of the feathers. The rectrices from one adult male collected in July 2012, two adult males and one adult female, and two juvenile males in August 2012, produced 

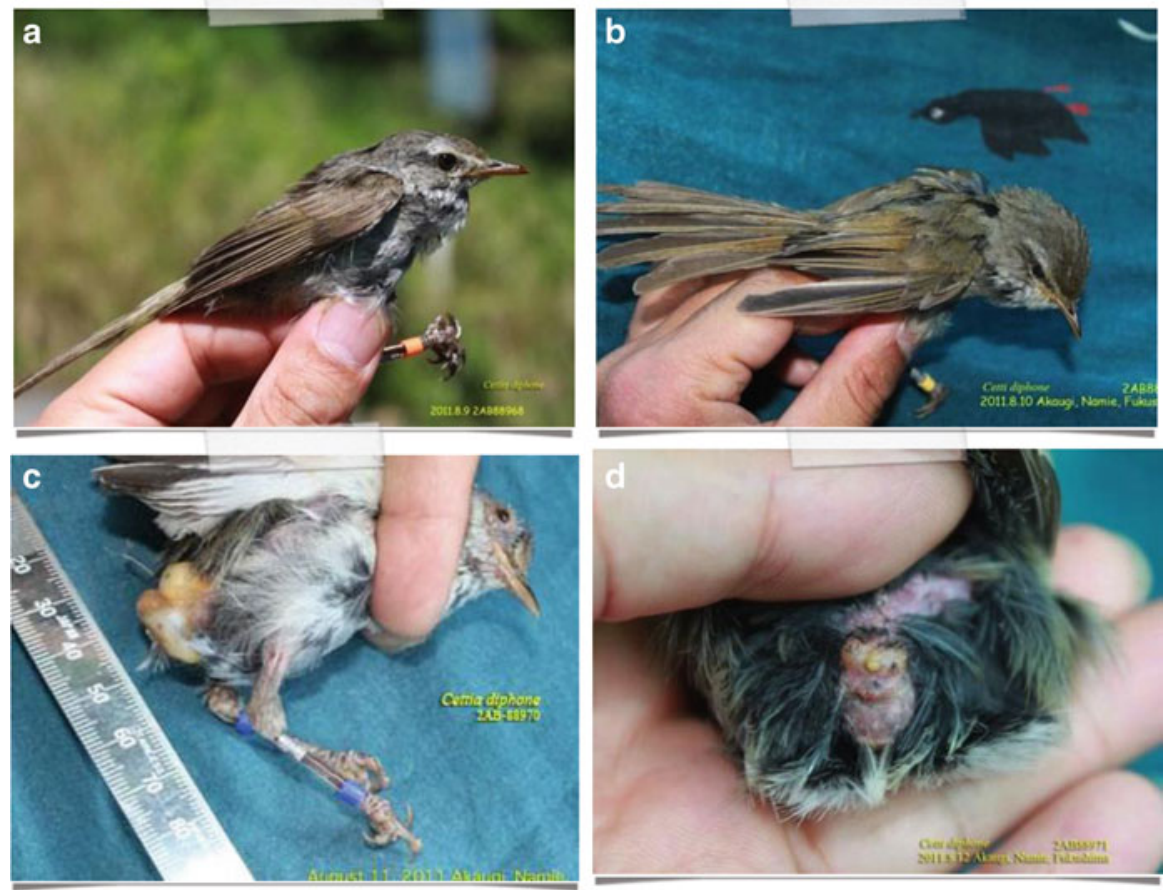

Fig. 12.5 Bush warbler males captured in highly contaminated areas of the Abukuma highlands. I caught these individuals in August 2011, when they were starting to molt

much weaker images after 3-5 days contact with IP. As indicated by Tanoi (2013), radioactivity was deposited on the leaves and ground after the accident, whereas newly grown leaves showed little or no contamination later in spring. Thus, birds that entered this area during the spring of 2012 appeared to have little contamination on their feathers. Birds that produced new feathers during late summer 2011 in this area should have some contamination both on the outside and from the inside.

The bush warbler usually migrates between its breeding and wintering sites. The distance ranges from $50 \mathrm{~km}$ east to $90 \mathrm{~km}$ south, e.g., the Chichibu Mountains in central Japan (K. Ishida, unpublished data). It is reasonable to assume that the population in Fukushima has almost the same migration habits as the Chichibu population because we can observe this warbler during the winter in the Hamadori and Nakadori areas. I observed a bush warbler during mid-March 2012 in the Abukuma highlands, although we had some snow accumulation at that time. Continuous automatic recording from winter through spring at 11 sites in this area, indicated that the warbler appeared (began to produce sounds) in mid-March in 2012. The differences in the temperature and snow accumulation between March 2011 and 2012 were 


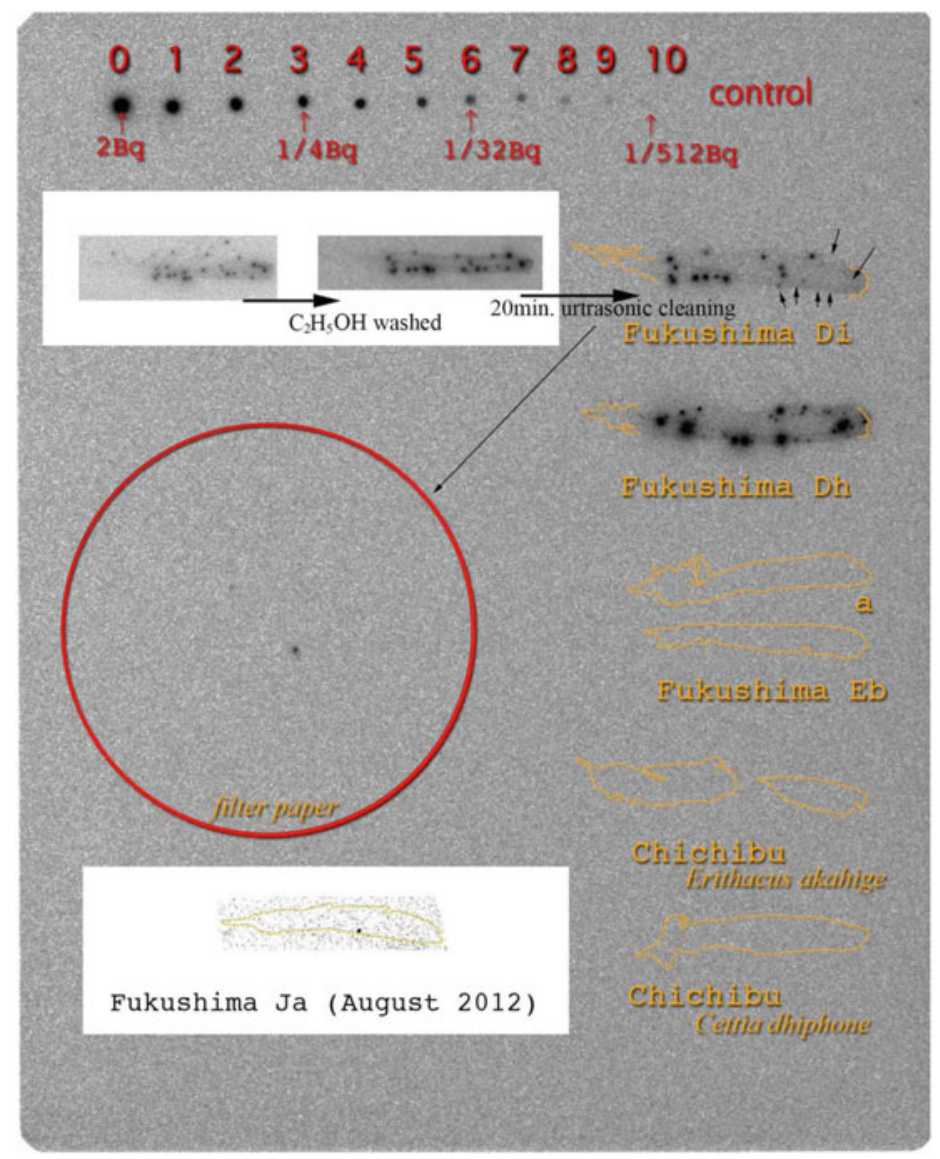

Fig. 12.6 IP figures of the bush warbler feathers, after 3 days of contact, D-h and D-i; Abukuma mountains, August 2011, E; Abukuma Mountains, October 2011, Ja; Abukuma Mountains, August 2012, Chichibu mountains, $250 \mathrm{~km}$ southwest of F1-NPP, August 2011 and October 2011. For D-i, the image shows a feather that was cleaned using Kimwipes and ethanol, followed by an ultrasonic cleaner. The Abukuma-August-2011 feather produced an abundance of contamination dots. The red circle indicates the paper filter contact image after percolation with the ultrasonic cleaning water of feather D-i. The outline of D-h and D-i feathers are clear and it indicates that the whole feather was highly contaminated. The thick dots indicate intensive (very high) radioactive contamination. The 11 control dots at the top indicate 2-Bq radiation and those, which are reduced sequentially twofold (from 2 to $1 / 512 \mathrm{~Bq}$ ) from left to the right

small. The first song of the bush warblers in mid-March was almost "perfectly" performed at this highland. These observations suggest that the males caught in mid-August had bred in the area with high radioactivity contamination for 5 months. However, we cannot ascertain whether they were present when the F1-NPP accident occurred on March 11, 2011.

My results and the habits of the bush warbler population in Fukushima suggest that examinations of feather contamination estimate the level of radiation exposure of individual birds. 


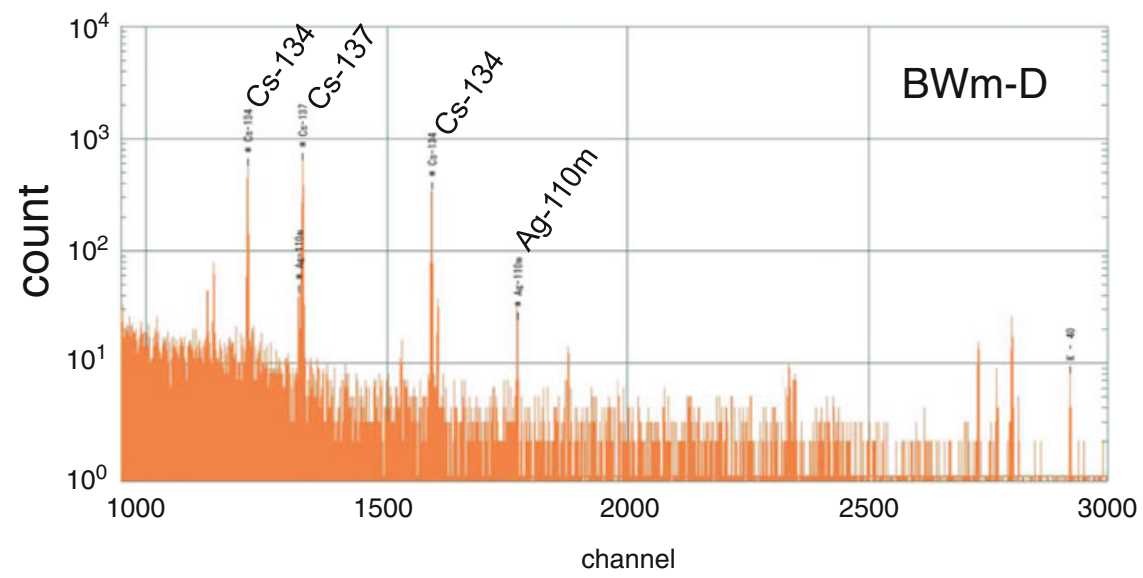

Fig. 12.7 The radioactivity profiles measured using a germanium semiconductor detector using eight rectrices from the individual D. ${ }^{134} \mathrm{Cs},{ }^{137} \mathrm{Cs}$, and ${ }^{110 \mathrm{~m}} \mathrm{Ag}$ were identified and the radioactivity was $12.5,17.3$, and $1.4 \mathrm{~Bq}$, respectively. The total weight of the eight feathers was approximately $56 \mathrm{mg}$ (Table 12.2)

Table 12.2 The contamination of feathers

\begin{tabular}{lllllll}
\hline & & & \multicolumn{2}{l}{ Radioactivity } & \\
\cline { 5 - 6 } Individual & No. of feathers & Total weight & ${ }^{134} \mathrm{Cs}$ & ${ }^{137} \mathrm{Cs}$ & ${ }^{110 \mathrm{~m}} \mathrm{Ag}$ & Date of capture \\
\hline A & 2 & $0.015 \mathrm{~g}$ & $0.2 \mathrm{~Bq}$ & $0.2 \mathrm{~Bq}$ & N.D. & August 9 \\
$\mathrm{~B}$ & 2 & $0.014 \mathrm{~g}$ & $2.5 \mathrm{~Bq}$ & $3.6 \mathrm{~Bq}$ & N.D. & August 10 \\
$\mathrm{C}$ & 4 & $0.026 \mathrm{~g}$ & $1.2 \mathrm{~Bq}$ & $1.8 \mathrm{~Bq}$ & N.D. & August 11 \\
$\mathrm{D}$ & 8 & $0.056 \mathrm{~g}$ & $12.5 \mathrm{~Bq}$ & $17.3 \mathrm{~Bq}$ & $1.4 \mathrm{~Bq}$ & August 12 \\
\hline
\end{tabular}

${ }^{a}$ The experiments were conducted by Dr. K. Tanoi from the University of Tokyo. The detection period was $0.7-3.0 \mathrm{~h}$

\subsection{Effects of Radioactivity on Bush Warbler and Boar}

One of the four bush warbler males had a "lesion looks very much like its due to avian poxvirus (dry chronic form)" (Lucio John Filippich, personal communication) around its cloaca (Fig. 12.5c). Almost the same appearance had been observed on the two males of the same bird species at Wakayama Prefecture, western Japan, in 2006 summer (Kumashiro et al., unpublished data). The lesions were not likely tumors but may be abscesses or dilatation of cutaneous glands, while histological examination was not performed (Hiroyuki Nakayama, personal communication). The same individual had Leucocytozoon protozoa in its blood, whereas the other three males did not (Koichi Murata et al., unpublished data). In the Chichibu mountains, blood parasite protozoa including Leucocytozoon spp. were found in $6 / 58$ bush warblers (Imura et al. 2012). We are processing the plasma samples of Bush warblers to examine their stress levels and behavior (Wingfield et al. 1995). 
Table 12.3 Total ${ }^{134} \mathrm{Cs}$ and ${ }^{137} \mathrm{Cs}$ levels in wild boar hind limb muscle

\begin{tabular}{lccc}
\hline Radioactivity level $(\mathrm{Bq} / \mathrm{kg})$ & $\begin{array}{l}\text { No. of individuals } \\
\text { Fukushima prefecture }\end{array}$ & $\begin{array}{l}\text { No. of individuals } \\
\text { other prefectures }\end{array}$ & \begin{tabular}{l} 
Date of capture \\
\hline $14,600^{\mathrm{a}}$
\end{tabular} \\
13,300 & 1 & & September 5th, 2011 \\
$8,000<$ & 2 & & \\
$4,000-8,000$ & 5 & 4 & \\
$2000-4,000$ & 30 & 4 & \\
$1,000-2,000$ & 59 & 8 & \\
$500-1,000$ & 32 & 14 & \\
$250-500$ & 17 & 22 & \\
$100-250$ & 6 & 20 & \\
\hline
\end{tabular}

Boars were hunted in Fukushima, Miyagi, Tochigi, and Ibaraki Prefectures between May 2011 and March 2012

The data is published in Japanese at the following URLs: http://wwwcms.pref.fukushima.jp/download/1/shizen23-inosisi.pdf

http://www.pref.miyagi.jp/sizenhogo/seibutu/honyurui/housyaseibussitukensa/housyaseikensa231205. pdf

http://www.pref.tochigi.lg.jp/kinkyu/d04/houshanou_choujuu.html http://savechild.net/wp-content/uploads/2011/09/syokuhin.gif

${ }^{\mathrm{a}} 33,000 \mathrm{~Bq} / \mathrm{kg}$ was reported from an individual captured on October 29, 2012 in Fukushima

Wild boars hunted in Fukushima and neighboring prefectures had various levels of ${ }^{134} \mathrm{Cs}$ and ${ }^{137} \mathrm{Cs}$ in their muscle (Table 12.3). The two highest levels were 14,600 and $13,300 \mathrm{~Bq} / \mathrm{kg}$, whereas more than half of those captured in Fukushima prefecture $\mathrm{had}>500 \mathrm{~Bq} / \mathrm{kg}$, as did many in other neighboring prefectures. The boar forages for animals and plants by digging through the litter on the ground and in the soil, which were highly contaminated with ${ }^{134} \mathrm{Cs}$ and ${ }^{137} \mathrm{Cs}$. It is possible that the boar consumed radioactive materials directly from the soil and through food. The earthworms were also highly contaminated with radioactivity in the area (Hasegawa et al., unpublished data), which resembled the food web effect of radioactivity in the woodcock in Norway 5 years after the Chernobyl accident (Kålås et al. 1994). A copper pheasant (Syrmaticus soemmerringii) hunted at Fukushima in November had $735 \mathrm{~Bq} / \mathrm{kg}$, whereas $5 / 10 \mathrm{had}>200 \mathrm{~Bq} / \mathrm{kg}$ total radiocesium in their muscle (Fukushima Prefecture). This endemic Japanese pheasant feeds on ferns in winter, which are also known to concentrate radioactivity like mushrooms. Because we have not yet little evidence of the direct effects of radioactivity on wildlife at Fukushima, we will continue to observe and collect samples.

\subsection{Factors that Affected the Wildlife}

The accident occurred on March 11, before plants had begun to produce their spring shoots and birds had begun breeding. There was still some snow accumulation in the highlands of Fukushima. Thus, plant and animal cells were inactive at the time of the highest radioactive exposure. Therefore, the direct and decisive effects of the 
radiation from F1-NPP were low at that time. No forest death caused by the F1-NPP accident was observed, even in forests very close to it.

Radioactivity levels of 20 or $80 \mu \mathrm{Sv} / \mathrm{h}$ can be detected around the highly contaminated ecosystem in the northwest area of F1-NPP, particularly close to the ground and in the litter. These levels are not sufficiently high to have obvious and direct results on the wildlife (Kryshev et al. 2005). The wildlife ecology is affected by various factors such as predators, pathogens, parasites, competitors, resource shortage, and low temperature. I caught healthy looking youngsters of bush warblers and their probable parents at a place with approximately $5 \mu \mathrm{Sv} / \mathrm{h}$ dose rate (1 $\mathrm{m}$ above the ground) on August 14th, 2012. Several other individuals caught in this area also looked healthy and I could record their normal songs even at a point approximately $10 \mathrm{~km}$ northwest of F1-NPP of $>40 \mu \mathrm{Sv} / \mathrm{h}$. In the northern Abukuma highlands of Fukushima, the lack of human activity is also an important factor that affects the wildlife. It has negative and positive effects depending on the ecology of each wild plant or animal. Thus, long-term and wide-range monitoring is required to understand the effects of the F1-accident and to distinguish the effects of radiation.

Open Access This article is distributed under the terms of the Creative Commons Attribution Noncommercial License which permits any noncommercial use, distribution, and reproduction in any medium, provided the original author(s) and source are credited.

\section{References}

Imura T, Suzuki Y, Ejiri H, Sato Y, Ishida K, Sumiyama D, Murata K, Yukawa M (2012) Prevalence of avian haematozoa in wild birds in a high-altitude forest in Japan. Vet Parasitol 183:244-248

Kålås JA, Bretten S, Byrjedal I, Njastad O (1994) Radiocesium (137Cs) from the Chernobyl reactor in Eurasian woodcock and earthworms in Norway. J Wildl Manage 56:141-147

Kryshev II, Sazykina TG, Bersfore NA (2005) Effects on the wildlife. In: Smith J, Beresford NA (eds) Chernobyl catastrophe and consequences. Springer, Berlin, pp 267-287

Møller AP, Hagiwara A, Matsui S, Kasahara S, Kawatsu K, Nishiumi I, Suzuki H, Ueda K, Mousseau TA (2012) Abundance of birds in Fukushima as judged from Chernobyl. Environ Pollut 164:36-39

Tanoi K (2013) Behavior of radiocesium adsorbed by the leaves and stems of wheat plant during the first year after the Fukushima Daiichi nuclear power plant accident. In: Nakanishi TM, Tanoi K (eds) Agricultural implications of the Fukushima nuclear accident. Springer, Tokyo

Tozawa A (2005) Birds. In: Nature, Haramachi city history Haramachi city (ed.), pp 606-655 (in Japanese)

Wingfield JC, Kubokawa K, Ishida K, Ishii S, Wada M (1995) The adrenocortical response to stress in male bush warblers, Cettia diphone: a comparison of breeding populations in Honshu and Hokkaido. Jpn Zool Sci 12:615-621 